\title{
Michał Preisner
}

AGH Akademia Górniczo-Hutnicza

e-mail: preisner@agh.edu.pl

\section{ANALIZA KORZYŚCI Z ZASTOSOWANIA SYMBIOZY PRZEMYSLOWEJ}

\section{ANALYSIS OF INDUSTRIAL SYMBIOSIS BENEFITS}

DOI: $10.15611 / \mathrm{pn} .2017 .494 .17$

JEL Classification: O13, O44, Q57

Streszczenie: W związku z przyjęciem przez Komisję Europejską ambitnego pakietu dotyczącego gospodarki o obiegu zamkniętym państwa członkowskie UE zostały zobligowane do zapewnienia wysokich poziomów w zakresie gospodarowania odpadami ze szczególnym uwzględnieniem ponownego użycia, recyklingu i odzysku. Jednym z narzędzi mogących się przyczynić do poprawy stanu aktualnego przez zawrócenie do obiegu materiałów i energii jest zainicjowanie symbiozy przemysłowej. Mająca ponad pół wieku koncepcja została zapomniana $\mathrm{z}$ powodu intensywnego wykorzystywania surowców naturalnych w gospodarce linearnej. Istnieją przedsiębiorstwa, które od lat stosują rozwiązania wpisujące się w koncept symbiozy, której inicjacja najczęściej spowodowana była wyraźnymi korzyściami finansowymi. Celem niniejszego artykułu jest analiza korzyści wynikających z zastosowania symbiozy przemysłowej na wybranych przykładach z państw UE oraz zestawienie ich z ewentualnymi wadami lub niezbędnymi nakładami inwestycyjnymi.

Słowa kluczowe: symbioza przemysłowa, gospodarka o obiegu zamkniętym, ekosystem przemysłowy, produkty uboczne, odpady, wymiana energii.

Summary: Due to the adoption of an ambitious package on circular economy by the European Commission, EU Member States have been obliged to provide high levels in waste management area with particular focus on re-use, recycling and recovery. One of the tools that can contribute to improving the current state by recycling materials and energy is to initiate industrial symbiosis. This concept has been forgotten due to the intensive use of natural resources following the linear economy model. However, there are companies that have adopted many years ago solutions fitting the idea of industrial symbiosis, which initiation was most likely a result of future significant financial benefits. The purpose of this article was to analyze the benefits of using industrial symbiosis on selected examples from EU countries and to compare them with possible defects or necessary investment expenditures.

Keywords: industrial symbiosis, circular economy, industrial ecosystem, byproducts, waste, energy exchange. 


\section{Wstęp}

Mimo że termin symbiozy przemysłowej został po raz pierwszy użyty dopiero w 1989 r., sama idea jest silnie związana z wyjątkowo aktualną koncepcją gospodarki o obiegu zamkniętym, która zakłada minimalizację wpływu na środowisko wytwarzanych materiałów poprzez projektowanie i wykonanie ich w sposób, który umożliwi ich powtórne wykorzystanie. Pakiet dotyczący circular economy został przyjęty przez Komisję Europejską w grudniu 2015 r. [European Commission 2015] i narzuca wiele wspólnych celów w zakresie odzysku, recyklingu i ponownego użycia do realizacji w państwach unijnych do 2030 roku.

Jedną z możliwości wdrażania gospodarki o obiegu zamkniętym jest symbioza przemysłowa, czyli współpraca dwóch lub większej liczby zakładów przemysłowych lub przedsiębiorstw, których odpady lub produkty uboczne jednego z nich stają się surowcem dla pozostałych [The Waste and Resources... 2016]. Podobnie jak ma to miejsce w przyrodzie, taki rodzaj synergii przynosi korzyści wszystkim uczestnikom symbiozy zarówno w aspekcie komercyjnym, jak i środowiskowym [Kronenberg, Bergier (red.) 2010, s. 137-138].

Symbioza przemysłowa najczęściej opiera się na fizycznej wymianie materiałów, energii, wody, produktów ubocznych lub współdzieleniu zasobów logistycznych. Postrzępione opony, tworzywa sztuczne lub para odpadowa z zakładów przemysłowych mogą zostać łatwo wymienione $\mathrm{z}$ innymi zainteresowanymi podmiotami.

Celem artykułu było przeprowadzenie analizy korzyści wynikających z zastosowania rozwiązań wpisujących się w ideę symbiozy przemysłowej na wybranych przykładach. Opisane w artykule przykłady symbiozy przemysłowej to: ekosystem przemysłowy w Kalundborgu w Danii, symbioza cukrowni i firmy budowlanej w Troyes we Francji, symbioza papierni i fabryki samochodów w Ghent w Belgii oraz współpraca zakładów nawozowych z lokalnymi rolnikami na rzecz zapobiegania eutrofizacji wód w południowej Finlandii. W wyniku analizy stworzono bilans, w którym zalety poszczególnych rozwiązań zestawiono z ich kosztami.

\section{Analiza istniejących przykładów symbiozy przemysłowej}

Dobór przykładów ilustrujących korzyści płynące z zastosowania symbiozy przemysłowej został dokonany w celu przedstawienia różnorodności obszarów, w których symbioza może zostać zainicjowana. W rezultacie opisana $\mathrm{w}$ artykule działalność podmiotów prowadzona jest m.in. w sektorach przemysłu spożywczego, energetycznego, papierniczego, samochodowego, ale również w sektorach komunalnym i rolniczym. Szczególna uwaga została poświęcona wykorzystaniu produktów ubocznych lub odpadów, tj. popiołów lotnych, siarki i osadów ściekowych i zagospodarowanej energii odpadowej powstałej w wyniku różnorodnych procesów produkcyjnych. 


\subsection{Kalundborg Symbiosis, Kalundborg, Dania}

Modelowym i jednocześnie najstarszym przykładem symbiozy przemysłowej zgodnie z zasadą bliskości jest duński ekosystem przemysłowy Kalundborg Symbiosis, którego początki sięgają lat 60., kiedy to przedsiębiorstwo energetyczno-naftowe Esso (obecnie Statoil) potrzebowało wody do swojej rafinerii w okolicach Kalundborga i poprowadziło rurociąg z pobliskiego jeziora Tissø [Kalundborg Symbiosis]. W 1973 roku przedsiębiorstwo energetyczne Asnæs Plant (obecnie Dong Energy) podłączyło się do istniejącego rurociągu Statoil. Zainicjowano w ten sposób symbiozę polegającą na czerpaniu wzajemnych korzyści dzięki współdzieleniu środków i surowców przez dwa podmioty. W kolejnych latach coraz więcej przedsiębiorstw zlokalizowanych w okolicach Kalundborga łączyło się w sieć współpracy, dokonując wymiany materiałów i energii. Dziś dzięki symbiozie m.in. odpady przedsiębiorstwa produkującego biofarmaceutyki - Novozymes wykorzystywane są do produkcji nawozów rolniczych, a wspomniane wcześniej Dong Energy, dzięki instalacji do odsiarczania spalin, sprzedaje wychwyconą siarkę firmie Gyproc do produkcji gipsu (rys. 1).

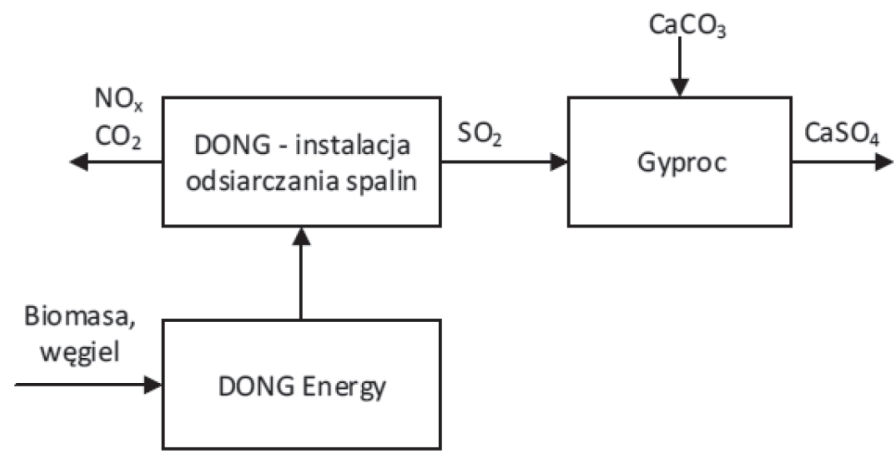

Rys. 1. Schemat fragmentu ekosystemu przemysłowego w Kalundborgu

Źródło: opracowanie własne na podstawie [Kalundborg Symbiosis].

Całą historię wymiany w Kalundborgu przedstawiono w tab. 1.

Tabela 1. Przedmioty wymiany w ramach symbiozy przemysłowej w Kalundborgu (Dania)

\begin{tabular}{|c|l|c|l|}
\hline Rok & \multicolumn{1}{|c|}{ Przedmiot symbiozy } & Rok & \multicolumn{1}{|c|}{ Przedmiot symbiozy } \\
\hline 1 & 2 & 3 & 4 \\
\hline 1961 & Woda powierzchniowa & 1995 & Ścieki \\
\hline 1972 & Gaz ziemny & 1995 & Odcieki wodne \\
\hline 1973 & Woda powierzchniowa & 1995 & Zużyty gips \\
\hline 1976 & Biomassa/NovoGro & 1998 & Osad \\
\hline 1979 & Popiół lotny & 1999 & Popiół lotny \\
\hline
\end{tabular}




\begin{tabular}{|c|l|c|l|}
\hline 1 & \multicolumn{1}{|c|}{2} & 3 & \multicolumn{1}{c|}{4} \\
\hline 1980 & Energia cieplna & 2002 & Woda zdemineralizowana \\
\hline 1981 & Energia cieplna & 2004 & Woda \\
\hline 1982 & Para wodna $(\times 2)$ & 2007 & Woda morska \\
\hline 1987 & Woda powierzchniowa & 2009 & Para wodna \\
\hline 1987 & Woda chłodnicza & 2009 & Kondensat \\
\hline 1989 & Drożdże & 2009 & Słoma \\
\hline 1990 & Nawóz siarkowy & 2010 & Bioetanol \\
\hline 1991 & Woda techniczna & 2010 & Węgiel brunatny \\
\hline 1992 & Gaz ziemny & 2010 & Cukry C5/C6 \\
\hline 1993 & Gips & & \\
\hline
\end{tabular}

Źródło: opracowanie własne na podstawie [Kalundborg Symbiosis].

Pionierski charakter symbiozy w Kalundborgu pokazuje także fakt, że miasto już w 1981 r. wykorzystywało energię z odpadów do zasilania miejskiej sieci ciepłowniczej.

O znacznych wzajemnych korzyściach współpracy podmiotów w Kalundborgu stanowi niewątpliwie bliskość prywatnych i państwowych przedsiębiorstw z różnych gałęzi gospodarki, co zdecydowanie ułatwia wymianę odpadów, produktów ubocznych oraz niewykorzystywanej energii. W obecnych czasach dystans nie stanowi już jednak problemu, szczególnie w przypadku materiałów o dużej wartości. Jedynie materiały o małej wartości, niskiej jakości lub energii cieplnej ze względu na koszty transportu i oddziaływanie na środowisko nie są brane pod uwagę w symbiozie znacznie oddalonych zakładów.

\subsection{Cristal Union i Appia Champagne, Troyes, Francja}

Drugi z poddanych analizie przykładów korzyści symbiozy przemysłowej pochodzi z Troyes we Francji. Symbioza zachodzi między zakładami produkcji cukru należącymi do firmy Cristal Union a przedsiębiorstwem budowlanym Appia Champagne. Symbioza została zainicjowana w 2004 r. i miała na celu pobudzenie rozwoju gospodarczego w regionie. Do produkcji cukru w zakładach Cristal Union wykorzystuje się buraki cukrowe w ilości ok. $25000 \mathrm{t} / \mathrm{d}$. W procesie produkcyjnym do płukania buraków stosuje się wodę. Zawierająca piasek o różnym składzie granulometrycznym woda jest poddawana podczyszczaniu, a piasek odzyskuje się w procesie sedymentacji. Piasek zawiera zanieczyszczenia, które uniemożliwiają stosowanie go w rolnictwie, jednak idealnie nadaje się do zastosowania w budownictwie. Na rys. 2 przedstawiono schemat symbiozy przemysłowej z udziałem Cristal Union i Appia Champagne.

Począwszy od 1964 r., ziemia pozostała po oczyszczeniu buraków była składowana w odległości do $30 \mathrm{~km}$ od Troyes, co w konsekwencji kosztowało firmę śred- 


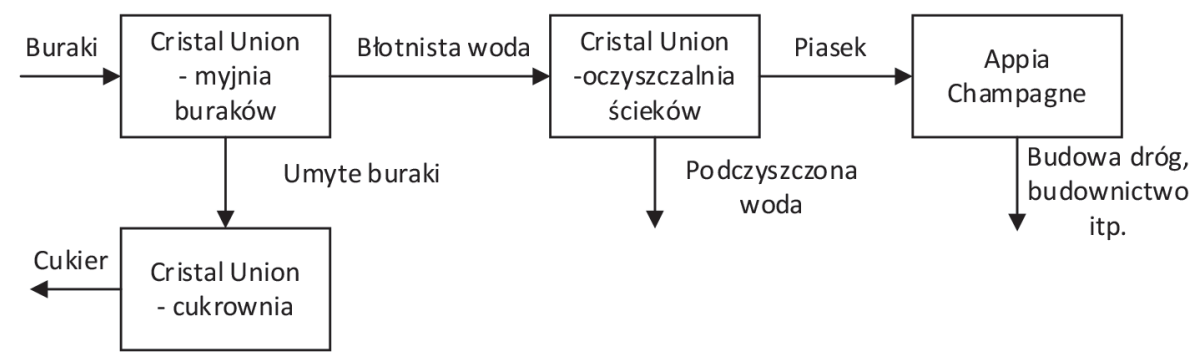

Rys. 2. Symbioza w przemysłu spożywczego i budowlanego w Troyes

Źródło: opracowanie własne na podstawie [Ecologie Industrielle \& Territoriale 2014].

nio 150-300 tys. euro rocznie [Ecologie Industrielle \& Territoriale 2014, s. 28-29]. Średnia produkcja cukru wynosi ok. 12500 t/d, natomiast ilość piasku powstała na skutek procesu płukania buraków wynosi ok. 300 t/d.

W 2004 roku Cristal Union uzgodniło z firmą Appia Champagne warunki umowy na odbiór piasku powstałego w cukrowni, kończąc w ten sposób okres kosztownego składowania produktu ubocznego. Appia Champagne zredukowała wydobycie piasku, ograniczając swoje koszty działalności. W aspekcie rozwoju regionalnego zlikwidowano również konieczność transportu piasku z innych regionów. Szacuje się, że pozwoli to oszczędzić ok. 40 tys. litrów paliwa rocznie, co przyczyni się do zwiększonej efektywności wykorzystania zasobów.

\subsection{Stora Enso i Volvo Cars, Ghent, Belgia}

Kolejny z analizowanych przykładów symbiozy przemysłowej został zainicjowany w 2016 r. w okolicy Ghent (Gandawa) w Belgii między papiernią Stora Enso a fabryką samochodów marki Volvo.

W zakładach papierniczych Stora Enso powstaje ok. 550000 ton gazet i magazynów rocznie. Cały nakład produkuje się z papieru pochodzącego z recyklingu. Rocznie zakład przetwarza ok. 700000 ton surowca wtórnego. Papiernia w Ghent jest w stanie pokryć do 75\% własnego zapotrzebowania na energię elektryczną oraz w całości zapotrzebowanie na parę przemysłową [Stora Enso 2014]. Papiernia wykorzystuje kocioł na biomasę, w której spalane są osady ściekowe i biomasa w celu produkcji energii odnawialnej. Aby jeszcze zwiększyć efektywność energetyczną, Stora Enso poszukuje nowych możliwości redukcji użycia paliw kopalnych oraz emisji gazów cieplarnianych. Dzięki współpracy z zakładami Volvo, po rocznej budowie powstał 4-kilometrowy rurociąg na parę wodną, który od listopada $2016 \mathrm{r}$. transportuje parę o temperaturze $125^{\circ} \mathrm{C} \mathrm{z}$ papierni Stora Enso do fabryki Volvo, gdzie jest ona wykorzystywana do celów grzewczych.

Symbioza spowodowała, że Volvo zredukowało ilość pobieranej energii z zewnątrz, przyczyniając się do redukcji emisji $\mathrm{CO}_{2}$ w wysokości 15000 ton rocznie, 
co stanowi łącznie $40 \%$ emisji $\mathrm{CO}_{2}$ z zakładu w Ghent, oraz koszty poboru energii na cele grzewcze. Roczne oszczędności z tytułu ogrzewania odpowiadają zaopatrzeniu w energię cieplną 5000 gospodarstw domowych. Schemat symbiozy przedstawiono na rys. 3.

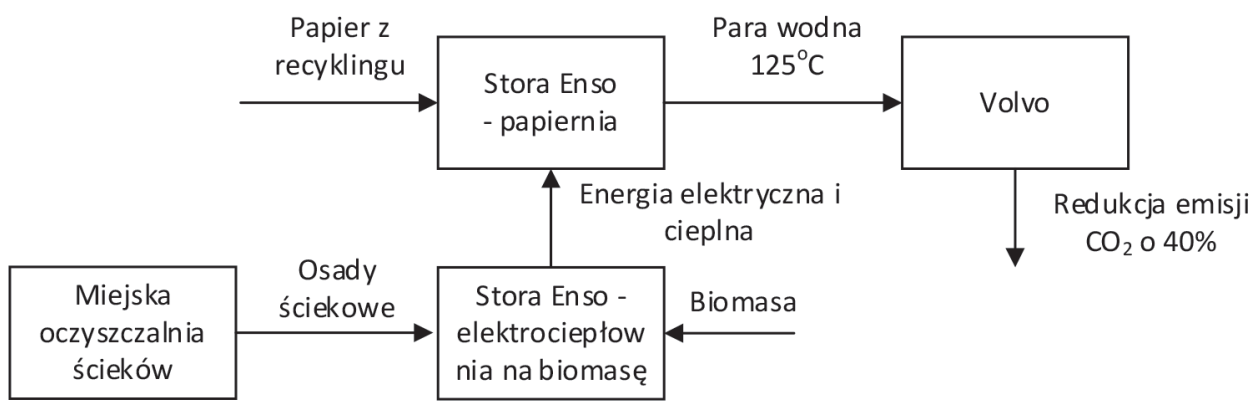

Rys. 3. Wymiana energii między Stora Enso i Volvo Cars

Źródło: opracowanie własne na podstawie [www.storaenso.com/newsandmedia/stora-enso-joins-forces-with-volvo-to-cut- $\mathrm{CO}_{2-}$ emissions].

\subsection{Yara Finland i gospodarstwa rolne w Siilinjarvi i Nurmijärvi, Finlandia}

Ostatni analizowany w artykule przykład symbiozy to synergia zakładów produkujących nawozy Yara i gospodarstw rolnych zlokalizowanych w południowej Finlandii.

Zakłady należące do Yara Finland od 1969 r. produkują głównie nawozy sztuczne, kwas fosforowy i chemikalia przemysłowe. Zakład składa się z kopalni i kilku instalacji do produkcji kwasu siarkowego, kwasu fosforowego, fosforanów kwasu azotowego i nawozów NPK. W tab. 2 przedstawiono produkcję w zakładach Yara Finland w Siilinjarvi.

Tabela 2. Produkcja w zakładach Yara Finland w Siilinjarvi

\begin{tabular}{|l|c|}
\hline \multicolumn{1}{|c|}{ Produkt } & Masa produktu (t/rok) \\
\hline Kwas siarkowy & 750000 \\
\hline Kwas fosforowy & 300000 \\
\hline Fosforany & 1000000 \\
\hline Kwas azotowy & 150000 \\
\hline Nawozy NPK & 500000 \\
\hline
\end{tabular}

Źródło: [http://yara.com/about/production_sites/finland_production_siilinjarvi.aspx].

Ponieważ zakłady Yara zlokalizowane są w regionie rolniczym, położonym w zlewni Morza Bałtyckiego szczególnie zagrożonym eutrofizacją [Dyrektywa 
Rady z dnia 21 maja 1991 r.], w 2008 r. podjęto próbę wykorzystania gipsu powstającego jako produkt uboczny w produkcji nawozów sztucznych do zatrzymania odpływu związków fosforu wraz ze spływem powierzchniowym do Morza Bałtyckiego. Przedsięwzięcie to zostało objęte projektem TRAP i polegało na wykorzystaniu powszechnie dostępnych maszyn rolniczych do rozrzucenia składowanego dotychczas gipsu po polach uprawnych na obszarze $2,4 \mathrm{~km}^{2} \mathrm{w}$ ilości $4 \mathrm{t} / \mathrm{ha} \mathrm{w}$ pobliżu miejscowości Nurmijärvi.

Jako rezultat wykorzystania gipsu zwiększono zdolność gleby do akumulacji fosforu, co skutkowało zmniejszeniem odpływu z terenów rolniczych rozpuszczonego fosforu o 33\% i fosforu całkowitego o 54\%. Przyczyniło się to również do poprawy jakości gleb w regionie [Aho i in. 2015, s. 16-17]. Na rys. 4 przedstawiono schemat przedsięwzięcia w południowej Finlandii.

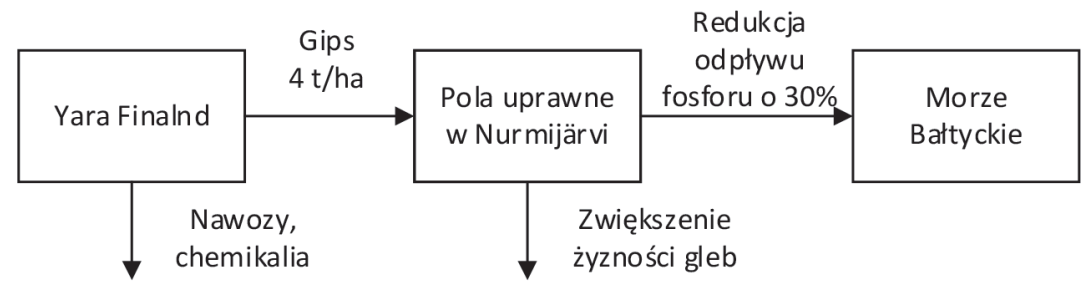

Rys. 4. Schemat wykorzystania gipsu do poprawy właściwości gleb

Źródło: opracowanie własne.

Projekt pokazał, że gips może być wykorzystany jako uniwersalny uszlachetniacz gleb, a jego zastosowanie poprawia retencję rozpuszczonego fosforu, ogranicza erozję i zmniejsza odpływ fosforu do wód powierzchniowych. Szacuje się, że zastosowanie gipsu zapobiegnie odpływowi 150000 ton fosforu do Morza Bałtyckiego. Ta ilość odpowiada prawie połowie wartości określonej jako cel przez HELCOM w planie działań na obszarach w pobliżu Morza Bałtyckiego w zakresie redukcji emisji fosforu. Wykorzystanie gipsu na polach uprawnych może kosztować $55 \mathrm{mln}$ euro, a jego oddziaływanie będzie odczuwalne przez 5 lat.

\section{Bilans wad i zalet symbiozy przemysłowej na podstawie omówionych przykładów}

Na podstawie opisanych $\mathrm{w}$ artykule przykładów symbiozy przemysłowej stworzono bilans wad i korzyści wynikających z zastosowania symbiozy przemysłowej (tab. 3).

Zestawienie pokazuje jasno, że korzyści znacznie przeważają nad wadami symbiozy. Analiza wskazuje również, że symbioza może mieć charakter środowiskowy, komercyjny (ekonomiczny) lub społeczny. 
Tabela 3. Bilans omówionych przykładów symbiozy przemysłowej

\begin{tabular}{|c|c|c|}
\hline $\begin{array}{c}\text { Miejsce } \\
\text { i zaangażowane } \\
\text { podmioty }\end{array}$ & Wady & Korzyści \\
\hline $\begin{array}{l}\text { Kalundborg } \\
\text { (Dania) } \\
\text { Statoil, } \\
\text { Dong Energy, } \\
\text { Novozymes, } \\
\text { Gyproc }\end{array}$ & $\begin{array}{l}\text { Niezbędne inwestycje } \\
\text { w różnego rodzaju } \\
\text { proekologiczne instalacje } \\
\text { umożliwiające pozyskanie } \\
\text { wymaganego w symbiozie } \\
\text { materiału }\end{array}$ & $\begin{array}{l}\text { - Zaoszczędzono } 3 \mathrm{mln} \mathrm{m}^{3} \text { wody dzięki jej } \\
\text { ponownemu wykorzystaniu i odzyskowi } \\
\text { - Uruchomiono produkcję biogazu z drożdży } \\
\text { wykorzystywanych w produkcji insuliny } \\
\text { - } \\
\text { Firma Gryproc uzyskała } 150 \text { tys. ton gipsu } \\
\text { dzięki odsiarczaniu spalin w zakładach } \\
\text { energetycznych Dong, przyczyniając się do } \\
\text { zachowania złóż naturalnych [Kalundborg } \\
\text { Symbiosis] }\end{array}$ \\
\hline $\begin{array}{l}\text { Troyes } \\
\text { (Francja) } \\
\text { Cristal } \\
\text { Union, Appia } \\
\text { Champagne }\end{array}$ & $\begin{array}{l}\text { Konieczność oddzielenia piasku } \\
\text { z płuczki buraczanej, osuszenie } \\
\text { i przesianie odpowiedniej } \\
\text { frakcji piasku }\end{array}$ & $\begin{array}{l}\text { - Cukrownia oszczędza 150-300 tys. euro } \\
\text { rocznie na wyeliminowaniu składowania } \\
\text { produktu ubocznego [Ecologie Industrielle \& } \\
\text { Territoriale 2014, s. 28-29]. } \\
\text { - Zwiększona efektywność wykorzystania } \\
\text { zasobów: zastąpienie przez Appia } \\
\text { Champagne surowca pierwotnego } \\
\text { (piasku) surowcem odzyskanym z procesu } \\
\text { przemysłowego } \\
\text { - Minimalizacja transportu piasku zmniejszyła } \\
\text { zapotrzebowanie na paliwo o ok. } 40 \text { tys. } \\
\text { litrów rocznie } \\
\text { Rozwój regionalny - uzyskano dodatkowe } \\
\text { źródło materiału budowlanego na inwestycje } \\
\text { w regionie }\end{array}$ \\
\hline $\begin{array}{l}\text { Ghent } \\
\text { (Belgia) } \\
\text { Stora Enso, } \\
\text { Volvo Cars }\end{array}$ & $\begin{array}{l}\text { Konieczność budowy } \\
\text { 4-kilometrowego rurociągu } \\
\text { i transport pary wodnej }\end{array}$ & $\begin{array}{l}\text { - Redukcja emisji } \mathrm{CO}_{2} \text { o } 15000 \text { ton rocznie } \\
\text { [Stora Enso 2014] } \\
\text { Oszczędność finansowa wynikająca } \\
\text { z redukcji poboru energii do } \\
\text { celów grzewczych odpowiadającej } \\
\text { zapotrzebowaniu } 5000 \text { gospodarstw } \\
\text { domowych } \\
\text { - Budowanie proekologicznego wizerunku } \\
\text { obydwu firm }\end{array}$ \\
\hline $\begin{array}{l}\text { Siilinjarvi } \\
\text { i Nurmijärvi, } \\
\text { (Finlandia) } \\
\text { Yara Finland, } \\
\text { gospodarstwa } \\
\text { rolne }\end{array}$ & $\begin{array}{l}\text { Zastosowanie gipsu jako } \\
\text { uszlachetniacza gleb nie } \\
\text { może być stosowane } \\
\text { w pobliżu jezior lub obszarów } \\
\text { wykorzystywanych do połowu } \\
\text { ryb ze względu na zawartość } \\
\text { siarczanów }\end{array}$ & 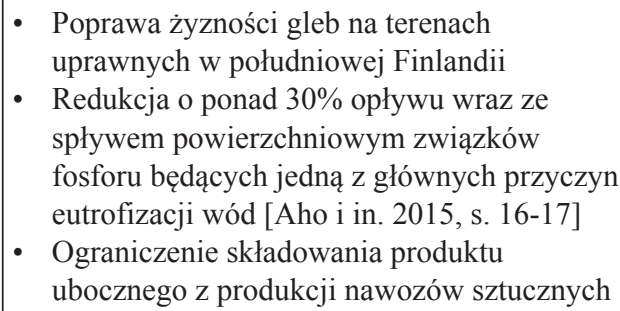 \\
\hline
\end{tabular}

Źródło: opracowanie własne 
Korzyści środowiskowe to:

- ograniczenie składowania i termicznego przetwarzania odpadów dzięki ich wykorzystaniu w pobliżu miejsca powstawania,

- zwiększenie efektywności wykorzystania materiałów i surowców naturalnych dzięki wykorzystaniu odpadów/produktów ubocznych/energii sąsiednich podmiotów,

- redukcja emisji $\mathrm{CO}_{2} \mathrm{i}$ innych zanieczyszczeń do atmosfery,

- minimalizacja poboru energii z zewnątrz.

Korzyści komercyjne (ekonomiczne) to:

- minimalizacja opłat za korzystanie ze środowiska i poboru energii z zewnątrz,

- redukcja kosztu transportu materiałów,

- poprawa wizerunku firm,

- możliwość sprzedaży produktów ubocznych i energii dotychczas niewykorzystywanych,

- rozwój innowacji i technologii.

- wsparcie gospodarstw rolnych (dotyczy symbiozy opartej na biomateriałach), np. przez zwiększenie żyzności gleb, pozyskanie nowego źródła wody do nawadniania upraw.

Korzyści społeczne zaś to nowe miejsca pracy dzięki powstaniu nowych modeli biznesowych.

Wady, jeśli występują, to są związane z niezbędnymi inwestycjami w nową infrastrukturę lub zmianę istniejącej, jak np. budowa 4-kilometrowego rurociągu na parę wodną w Ghent.

\section{Zakończenie}

Przykład Kalundborg Symbiosis wskazuje, że symbioza przemysłowa nie została wynaleziona, lecz naturalnie ewoluowała w ciągu kilku ostatnich dekad. Podmioty zaangażowane $\mathrm{w}$ symbiozę przemysłową mogą znajdować się w pobliżu lub w dalszej odległości, produkować podobny rodzaj produktu lub zupełnie inny.

Warto zauważyć, że przykłady symbiozy przemysłowej występują na całym świecie i mogą mieć zupełnie inną formę ze względu na odmienne uwarunkowania gospodarcze lub związane z ich lokalizacją czy też klimatem. Bardzo interesująco zapowiada się m.in. inwestycja polegająca na modernizacji ekoparku przemysłowego w Kawasaki w Japonii. Według szacunków korzyści z wykorzystania pełnego potencjału symbiozy przemysłowej w Kawasaki mają przekroczyć nawet 3-krotnie korzyści osiągane w Kalundborgu związane z pozyskaniem produktów ubocznych procesów przemysłowych (gipsu, siarki, popiołów lotnych, żużla i osadów ściekowych) [Van Berkel i in. 2009].

Zaprezentowane w artykule przykładowe wady są bezpośrednio związane z procesem technologicznym przedsiębiorstw objętych symbiozą. Należy jednak pamiętać, że tak jak wszystkie działania mające na celu redukcję zużywanych zasobów 
naturalnych powodują one pośrednie skutki negatywne objawiające się m.in. spadkiem zatrudnienia w sektorze wydobywczym, co w regionach górniczych ma realny wpływ na zamożność i poziom życia społeczeństwa. Dlatego też zadaniem i obowiązkiem obecnych i przyszłych rządzących jest podążanie taką drogą do gospodarki o obiegu zamkniętym, która pozwoli na minimalizację skutków spadku zatrudnienia w sektorach mniej efektywnych pod względem wykorzystania zasobów.

\section{Literatura}

Aho M., Pursula T, Saario M., Miller T., Kumpulainen A., Päällysaho M., Kontiokari V., Autio M., Hillgren A., Descombes L., 2015, The economic value and opportunities of nutrient cycling for Finland, Helsinki, s.16-17.

Dyrektywa Rady z dnia 21 maja 1991 r. dotycząca oczyszczania ścieków komunalnych (91/271/EWG).

Ecologie Industrielle \& Territoriale, 2014, Guide pratique de mise en oeuvre d'un écosystème industriel à travers une démarche d'Ecologie Industrielle et Territoriale, Ecologie Industrielle \& Territoriale, Rodan-Alpy, s. 28-29.

European Commission, 2015, Closing the loop - An EU action plan for the Circular Economy, Bruksela, http://ec.europa.eu/environment/circular-economy/index_en.htm (3.08.2017).

http://yara.com/about/production_sites/finland_production_siilinjarvi.aspx (15.08.2017).

Kalundborg Symbiosis, A circular ecosystem of economy, http://www.symbiosis.dk/en/evolution, Kalundborg (12.08.2017).

Kronenberg J., Bergier T. (red.), 2010, Wyzwania zrównoważonego rozwoju w Polsce, Fundacja Sendzimira, Kraków, s. 137-138.

Stora Enso, 2014, Stora Enso joins forces with Volvo to cut CO2 emissions, Sztokholm, www.storaenso. $\mathrm{com} /$ newsandmedia/stora-enso-joins-forces-with-volvo-to-cut- $\mathrm{CO}_{2-}$ emissions.

The Waste and Resources Action Programme 2016, What is industrial symbiosis?, Banbury. http:// www.wrap.org.uk/content/what-industrial-symbiosis (2.08.2017).

Van Berkel R., Fujita T., Hashimoto S., Fujii M., 2009, Quantitative Assessment of Urban and Industrial Symbiosis in Kawasaki, Japan, Environ. Sci. Technol., 43(5), s. 1271-1281.

Yara, Production Sites, Siilinjärvi, Finland. 